\title{
A CONSTRUÇÃO DA REALIDADE NA PERSPECTIVA RELACIONAL DE PIERRE BOURDIEU
}

\section{Danilo Manoel Farias Da Silva}

RESUMO: Falar do que vem a ser a "construção da realidade" é um tema transdisciplinar e interdisciplinar envolvendo distintas abordagens cientificas. Esse problema está presente desde a filosofia (vontade e representação), passando pela linguística (linguagem estruturando a realidade/construção da realidade social), a psicanálise (princípios da realidade psíquica), sociologia (construção social da realidade), antropologia (significação da norma cultural/formas de representação) e até a física teórica (visão da matéria na relação com o objeto/ posição do observador no espaço). No entanto, por mais que esse debate no nosso campo das ciências sociais seja conhecido a partir da sociologia do conhecimento (Berger e Luckmann), este trabalho se propõe a uma abordagem diferente a partir da perspectiva relacional de Pierre Bourdieu. Este ensaio tem como objetivo uma sistematização metodológica da discussão acerca da construção da realidade no pensamento de Bourdieu, além de discutir acerca do caráter social e cientifico que envolve a compreensão do que vem a ser a "realidade" e as possibilidades de sua representação, percepção e decodificação.

PALAVRAS-CHAVE: construção da realidade; percepção; representação; Bourdieu; perspectiva relacional; metodologia; epistemologia.

ABSTRACT: Talking of which happens to be the "construction of reality" is
a transdisciplinary and interdisciplinary topic involving different scientific approaches.
This problem is present from philosophy (Will and Representation), on linguistic (language
structuring reality / construction of social reality), psychoanalysis (principles of psychic
reality), sociology ( social construction of reality), anthropology (cultural norm / forms
of representation ) and even theoretical physics (view of matter in relation to the object /
observer's position in space). However, much as this debate in our field of social sciences 
is known as the sociology of knowledge (Berger and Luckmann), this work proposes a different from the relational perspective of Pierre Bourdieu's approach. This essay aims to systematize a methodological discussion about the construction of reality in the thinking of Bourdieu, besides discussing about the social and scientific character which involves understanding what becomes "reality " and the possibilities of their representation, perception and decodification.

KEYWORDS: construction of reality; perception; representation; Bourdieu; relational perspective; methodology; epistemology.

\section{INTRODUÇÃO}

A junção de distintas áreas do conhecimento científico além de ser um horizonte possível é uma bandeira que acompanha o novo movimento da teoria social contemporânea. Por mais que o histórico da ciência seja uma constituição positivista, o que favorece abordagens ortodoxas e reducionistas do mundo social, isso hoje vem caindo, e o que se erguem são castelos de novas metodologias interdisciplinares e transdisciplinares que se esforçam para apreender epistemologicamente as nuances do movimento do real.

O debate da articulação entre agência e estrutura, a guinada lingüística, a junção conceitual das metodologias que compõem os distintos campos das ciências sociais, são exemplos do esforço oriundo dos cientistas que tem um laboratório que está em constante movimento, à sociedade. A árdua missão desses cientistas é que, a sua maneira e com as ferramentas metodológicas que seu campo dispõe, eles se lançam na compreensão do mundo social, na explicação dos fenômenos e no descobrimento das leis causais da realidade manifesta no mundo social e material.

Desde os antigos gregos, os pilares desse conhecimento se formam na tríade dimensional dialética da: estrutura social (ethos), mente (eidos) e corpo (héxis). A sociologia, ciência política, demografia e antropologia, traçam paralelos de estudo com essas três dimensões do mundo (estrutura social- corpo- mente). Elas permeiam todas as bases do conhecimento cientifico sobre o que vem a ser a realidade manifesta, ou como diria Heráclito, o logos dialético.

Temáticas, Campinas, 22, (44): 61-86, ago/dez. 2014 
Cada campo cria metodologias de análises para estudar relacionalmente o logos dessa tríade dialética. Por exemplo, a estrutura social é objeto da ciência política, economia política e sociologia. O corpo, a antropologia, a etnometodologia, as perspectivas interacionais e a demografia. A mente, a fenomenologia, a psicanálise e a psicologia social.

Cada campo, com seus recursos metodológicos em mãos, se lança em apreender uma parte deste complexo movimento do real. Sendo que, por mais que percebemos a dialética como três movimentos distintos da constituição da realidade manifesta (tese, antítese e síntese no princípio dialético / estrutura social, corpo e mente no logos / simbólico-imaginárioreal na dialética psíquica/ pai, filho e espírito santo na escolástica metafísica...), ela faz parte do todo enquanto unidade da realidade (ou totalidade).

O problema que envolve todas as áreas do conhecimento é a "realidade". Cada ciência com a sua particularidade estrutura métodos para apreender o real em diferentes perspectivas, mas que não deixam de se relacionar com o logos da tríade dialética das múltiplas determinações da realidade estruturada no mundo social e estruturante de nossa ação e percepção nesse mundo. Desse modo, o objetivo deste ensaio é debater acerca do que vem a ser a realidade e os fundamentos de sua constituição social.

A "construção da realidade" é um tema que envolve distintas áreas do conhecimento cientifico. Esse problema está presente desde a filosofia (vontade e representação), passando pela lingüística (linguagem estruturando a realidade), a psicanálise (princípios da realidade psíquica), sociologia (construção social da realidade), antropologia (norma cultural do real) e até a física teórica (visão da matéria na relação com o objeto); não ficando a demografia e a ciência políticas alienadas do debate do que vem a realidade, já que ambas tem que se debruçar na sua apreensão.

Em nosso campo, o debate mais conhecido foi feito a partir da sociologia do conhecimento desenvolvida por Schutz (1962) e sistematizada por Berger e Luckmann (1996). Esses afirmam que na socialização primária, a mais entrincheirada na consciência, é onde o primeiro mundo é formado pela construção social da realidade. No entanto, por mais que a 
sociologia do conhecimento traga importantes contribuições, ela fica presa ao movimento da interioridade na exterioridade, faltando articular também em seu quadro as disposições geradas pela exterioridade na interioridade.

O sociólogo que procurou articular esses dois movimentos em seu quadro conceitual foi, Pierre Bourdieu, a partir de seus conceitos de habitus e campo, tendo a prática como centralidade teórica ${ }^{1}$. Ele articulou em sua metodologia os três clássicos (Marx, Durkheim e Weber), antropologia estrutural (Lévi-Strauss), interacionismosimbólico (Goffman), lingüística (Bakhtin), psicanálise (Freud), sem esquecer a fenomenologia de sua formação inicial em filosofia (Merleau-Ponty). Dito isto, o debate da construção da realidade vai ser feito a partir da perspectiva relacional desenvolvida por Bourdieu, sendo o ethos aproximado pelo conceito de campo, o eidos, esquemas mentais interiorizados, e a héxis, consubstanciada enquanto pratica social pelo habitus.

Neste texto que se apresenta, primeiramente vamos discutir sobre a contribuição metodológica da discussão acerca da construção da realidade para as ciências sociais; na segunda parte vamos discorrer sobre o problema social da realidade e suas implicâncias políticas e teóricas (sociológicas). Já nas duas últimas partes vamos apresentar o debate da construção da realidade sistematizados na perspectiva relacional de Bourdieu, vendo até que ponto o real é relacional.

\section{AS MÚLTIPLAS DETERMINAÇÕES DO REAL E O PROBLEMA DO CONHECIMENTO NA CIÊNCIA}

O tema da construção da realidade está presente no sistema de pensamento de Pierre Bourdieu, por mais que não apareça como aspecto central de sua teoria. A epistemologia desta problemática é determinante

\footnotetext{
${ }^{1}$ Outros também formularam mediações metodológicas, como Habermas articulando sistema e mundo da vida sendo a comunicação uma centralidade conceitual; e Foucault que a colocou para o discurso. No entanto, a comunicação e discurso são oriundos da língua como prática social (HANKS, 2008). Por isso optamos pela sociologia da prática desenvolvida por Pierre Bourdieu.
} 
no que diz respeito à compreensão do mundo social em seus distintos fenômenos, já que a relevância do que vem a ser a realidade é de supraimportância para a ciência de maneira geral. O sociólogo defende que:

\begin{abstract}
A "realidade social" de que falam os objetivistas também é um objeto de percepção. E a ciência social deve tomar como objeto não apenas essa realidade, mas também a percepção dessa realidade (...). A sociologia deve incluir uma "sociologia da percepção do mundo social", isto é, uma sociologia da construção das visões de mundo, que também contribuem para a construção desse mundo. (BOURDIEU, 2004. p. $156-7$ [1930]).
\end{abstract}

A construção das visões de mundo está no cerne do problema da constituição da realidade, e sempre esteve epistemologicamente presente desde a gênese do campo das ciências sociais nos clássicos. Para Marx (2007 [1845-6]), o desenvolvimento efetivo da realidade mostra que a consciência vem depois do ser social. Nesse caso o real se estrutura enquanto reflexo constitutivo da ontologia do ser social; vemos com isso: "uma noção de interação social - ou, "relações sociais", se apresenta de forma bastante clara. Em a ideologia alemã, eles a colocaram no centro da constituição e reprodução da vida social" (DOMINGUES, 2008. p. 23). Nessa gênese de uma teoria da interação, o real aparece enquanto atividade humana incorporada na consciência a partir do modo de produção da vida material. Por mais que a centralidade da teoria marxista tenha se formado na historicidade e no trabalho, o debate da construção do real enquanto atividade já se encontrava presente.

Durkheim (1996 [1912]) nas Formas Elementares da vida Religiosa propõe uma guinada que se caracteriza pela passagem da consciência coletiva para as representações coletivas, como conceito-chave da análise sociológica. Esta proposta de avanço em relação a Kant, se forma a partir da noção de representação coletiva enquanto categoria da vida mental do homem. Com isso, o que representamos do real não é produto de 
nossas cabeças enquanto razão pura, e sim construção social coletiva da realidade. Nosso julgamento de realidade não é algo natural, pressentimos as contingências das formas superiores do real (nomos), e não a realidade como um todo. Por isso, a vida coletiva e a mental são estruturadas pela via da representação (DURKHEIM, 1951 [1898]).

Já Weber na Objetividade do Conhecimento nas Ciências Sociais (2006 [1904]), discute que não se apreende a realidade na totalidade devido às infinitas possibilidades no espaço-tempo. Isso gera um problema na "objetividade" do conhecimento, porque a ciência não consegue captar a totalidade do mundo real. Desse modo, o que resta aos sociólogos é compreender as "leis", repetições regulares que formam uma frequência lógica enquanto estruturação racional da ação. Nesse ínterim, o problema da apreensão do real para Weber está diretamente associado ao nosso campo, já que: "a ciência social que nós pretendemos praticar é uma ciência da realidade. Procuramos compreender a realidade da vida que nos rodeia, e na qual nos encontramos situados". (WEBER, 2006. p. 44 [1904]).

$\mathrm{Na}$ sociologia, por mais que um dos primeiros a teorizar diretamente sobre esse assunto tenha sido Simmel, onde a partir do conceito de associação ele discute a metafísica da realidade (VANDENBERGHE, 2005). Esse debate é conhecido em nosso campo a partir da sociologia do conhecimento desenvolvida por Schutz e sistematizada por Berger e Luckmann (2009). Esses partindo de uma fenomenologia da ação que avança em relação ao mentalismo de Husserl (1989), afirmam que na socialização primária, a mais entrincheirada na consciência, é onde o mundo é formado pela construção social da realidade.

Em outros campos, como o da linguística, John Searle (1995) desloca a atenção para a questão estrutural do signo linguístico que nos interpela, sendo a realidade estruturada pela linguagem. Nessa perspectiva, os atos de fala são constituídos por regras de linguagem que exercem uma função de significado externo ao indivíduo, um opus operatum como fala Saussure, que se impõe mente.

Já na psicanálise, desde Freud (1900) a realidade funciona como uma construção do aparelho psíquico que tem a força do sentido produzida nas 
representações da realidade objetiva enquanto formação relacional com a realidade psíquica da memória e do inconsciente. Aprofundando esse debate, Lacan (1975) discute acerca da impossibilidade da realidade em si, existindo apenas como ilusão que se forma perante a percepção; e a divide em três movimentos que se articulam, o "simbólico -imaginárioreal" (SIR) que juntos formam a estrutura da representação.

Observamos que o debate acerca do que vem a ser o real é desenvolvido em diferentes sistemas de pensamento, sendo o ponto de consenso à existência de uma construção da realidade, que é o tema onde pretendemos contribuir no debate com este texto. Se há uma construção da realidade, é porque a perspectiva relacional já a precede. $O$ real é relacional. Por isso a realidade não é em si, fechada, e sim uma construção coletiva que se impõe visão (ens realissimuum) enquanto possibilidade da percepção, representação e decodificação do real.

Dito isso, vamos procurar responder no decorrer do texto um antigo paradoxo: o que ocorre é como diz Searle uma "construção da realidade social", ou como diz Berger uma "construção social da realidade"? É a estrutura social que impera sobre o indivíduo (Durkheim) ou a agência do sujeito que constrói a estrutura (Weber)? A ênfase se consubstancia no objetivismo estruturalista (Saussure) ou no subjetivismo fenomenológico (Husserl)?

Recaímos nessas concepções relacionais expressas ao mesmo tempo pela "interiorização da exterioridade e a exteriorização da interioridade". Sendo que, essa proposição necessita ser hermeticamente articulada, já que esses dois movimentos acontecem ao mesmo tempo, como no sentido de uma tríade dialética que se forma a partir de uma dualidade na unidade e unidade na dualidade como diria Simmel. Essa dimensão relacional é o que Bourdieu chama de mediação simbólica.

Nesse âmbito, partimos do pressuposto da perspectiva relacional como superna formulação para se analisar a construção da realidade. Pierre Bourdieu tem sua metodologia como um dos melhores quadros da sociologia contemporânea na articulação da agencia e estrutura como mediação simbólica, conectando ao mesmo tempo a estrutura social 
e a estruturação da ação na prática social estruturada (ORTIZ, 1994; DOMINGUES, 2008; MICELI, 2009).

Pensando com ele, e antes dele, Aristóteles, Descartes, Hume e Kant na gênese de uma ontologia do conceito de habitus na teoria do conhecimento (MEUCCI, 2009), existem três dimensões de sentido enquanto formação disposicional do real. O ethos, a héxis e o eidos. Podemos visualizar na operação abaixo:

- Ethos: estrutura social, ética, valores, espírito que se incorpora nos costumes e nas instituições sociais. / Campos de estudo: economia, direito, história, ciência política, sociologia, administração pública, lingüística funcional, dentre outras.

- Héxis: estrutura corporal, corpo biológico socializado, segunda natureza, ação social, prática concreta. /Campos: biologia, sociologia das interações (interacionismo simbólico, etnometodologia), sociologia da prática, linguística interacional, antropologia etnográfica, geografia espacial, demografia...

- Eidos: estrutura mental, idéias, imaginário, cognição, conceitos mentais, psiquismo/Campos: filosofia da mente, fenomenologia, psicanálise, psicologia, neurolinguística, neurobiologia, antropologia cultural, etc.

É como se cada campo estivesse pesquisando a sua maneira (com seus métodos e técnicas) uma ou mais determinações do real na construção social da realidade, enquanto que na verdade, o real em sua totalidade é fruto de múltiplas determinações. Essas três dimensões supracitadas se atravessam relacionalmente. Até hoje as ciências sociais buscam um caminho do meio na síntese metodológica da apreensão da realidade. Tem-se o eterno retorno a um antigo problema filosófico: mente x corpo; individuo x coletividade. Qual o mais importante na formação do mundo social na estrutura do real?

O pressuposto de que partimos é que não existe uma determinação mais forte, mas a junção de todos como um continuum (conti-nUM) é que estrutura o que vem a ser a realidade. Nesse caso, estrutura social, mente e corpo; fazem parte de um mesmo continuum dialético, e podem ser 
articulados, possibilitando com isso uma ampla compreensão do mundo social $^{2}$.

O debate científico mais heterogêneo nas ciências sociais vem procurando um caminho do meio para articular as distintas dimensões que compõem a realidade, conectar agencia e estrutura numa terceira via, formar um novo movimento teórica, uma perspectiva relacional, etc. No consensual, lingüística é um desses articuladores, já que o simbólico e o uso da estrutura da língua perpassa todos os campos. A realidade só se codifica a partir do verbo. Desde o diálogo socrático entre Crátilo e Hermógenes, no embate a propósito de decidir o nome e a coisa, Platão, antes de Saussure, discute a gênese de uma ciência do signo (linguístico) ao afirmar sobre o veio fluido de onde provêm os primeiros elementos para construção do conhecimento, no que concerne a natureza da linguagem (MAFRA, 2000).

No entanto, por mais que esses antigos e novos esforços estejam sento feitos, a "ciência ortodoxa" insiste em colocar cada campo aprisionado em seu quadrado metodológico, cada área com sua especificidade reducionista, criando e fixando barreiras monolíticas do conhecimento enquanto na verdade as coisas do mundo estão todas conectadas entre si (continuum). Do mesmo modo que a divisão do trabalho social aliena os trabalhadores para Marx, no reducionismo do campo cientifico (divisão do trabalho cientifico) também se aliena os pesquisadores no que diz respeito à apreensão da realidade.

Dito isso, a proposta deste ensaio é uma propor uma discussão acerca do que vem a ser a realidade, quais os mecanismos que estruturam a construção dessa realidade, os modos de percepção e representação do real

\footnotetext{
${ }^{2}$ Ainda na ontologia das múltiplas determinações do habitus, há mais duas dimensões no conceito aristotélico. Uma é o de diathesis, que é um estágio intermediário da ação, quando ainda vão vira corpo (hexis), o que abre brechas para pesquisas sobre reestruturação/ mudanças do habitus (DA SILVA, 2013). O outro é o de animus, sendo definido por Aristóteles (2000 [1 a.C]) como o estado de espirito que anima a matéria. O primeiro conceito aparece na teoria de Bourdieu e Lahire como sendo a disposição. Já o ultimo requer uma digressão em torno da metafísica e da fenomenologia transcendental, bem como dos estudos da matéria pela física quântica. Por isso, neste texto vamos nos deter ao materialismo das ciências sociais, porém numa perspectiva relacional.
} 
para o sujeito, as similitudes e diferenças entre o real e a realidade. Porém, antes precisamos delimitar a importância social do debate da construção da realidade enquanto fundamento sociológico do problema, para em seguida nos adentrarmos nas questões metodológicas do conhecimento social da realidade em Bourdieu.

\section{A QUESTÃO SOCIAL DA REALIDADE}

Na perspectiva positivista do mundo, é como se a realidade existisse em sua totalidade como sendo uma coisa em si no sentido Kantiano, independe espacialmente e temporalmente de maneira fechada, sem nenhuma relação direta com os agentes sociais que dela fazem parte. Com isso, todos veem e percebem tudo igualmente (como se tivessem os mesmos códigos) e assim podem orientar sua ação em direção racional a um fim especifico na realidade, como afirmam os utilitaristas e funcionalistas.

Nesse sentido, a percepção da realidade se estrutura a partir de premissas que justificam a construção do discurso capitalista neoliberal, nesse quem se esforça consegue tudo (meritocracia), como se não existisse nenhuma barreira da desigualdade social que afastam simbolicamente os indivíduos. Desse modo, os juristas afirmam que "todos são iguais perante a lei”, podemos dizer com isso que nessa perspectiva todos são iguais perante a realidade que os cerca. É a partir desse discurso de aparência republicana que se articula todo o pensamento meritocrático defendido pelo funcionalismo, onde na necessidade funcional da estratificação, as posições são naturalmente desiguais e os indivíduos tem uma orientação do self de maneira satisfatória na sua prática de acordo com essa regra social, conseguindo com isso a satisfação do ego (DAVIS e MOORE, 1979).

Nessa visão de mundo, a desigualdade aparece como algo natural sofrido por aqueles que não se esforçaram o suficiente para chegar às mais altas posições da hierarquia social. Tal leitura esquece a construção desigual dos indivíduos históricos, com condicionamentos sócio-psíquicos 
distintos, além da estrutura de reprodução social onde se estruturou em nossos pais uma estrutura de classe, raça e gênero como diz Gilberto Freyre (2006 [1936]). Enquanto um grupo foi educado em sobrados, o outro teve o sentido do mundo engendrado nos mucambos, se estabelecendo com isso uma estrutura de distribuição desigual dos capitais na economia simbólica da construção da realidade.

A mesma economia simbólica que forma a realidade é a que mantém o poder simbólico que encobre a dominação e reprodução social, os mantendo invisíveis ao olho. Percebemos como natural em nosso princípio da visão (o real apreendido), o que foi desigualmente naturalizado em nosso em nossa consciência (TAYLOR, 1997). Essa dimensão natural da ordem social é o que torna a desigualdade invisível perante os olhos do senso comum, pois a naturaliza (SOUZA, 2009).

Toda reprodução social se mantém a partir da manutenção da ordem simbólica (DURKHEIM, 1996 [1912]) e (FREUD, 2006 [1913]). Quando ordem das coisas essa se ancora ao mesmo tempo na estrutura social e em nosso aparelho psíquico (adequação entre as estruturas objetivas e subjetivas), acaba se estabelecendo não só a manutenção de um código cultural e linguístico, mas toda a estruturação dóxica de dominação e desigualdade que está presente nas relações sociais constituídas no senso comum.

Aqui, Bourdieu baseia-se polemicamente na fenomenologia do mundo de Husserl. De acordo com Husserl, o mundo do senso comum, nosso mundo ordinário, cotidiano, é um domínio da "doxa passiva", um domínio em que o real é tomado como dado e evidente em sua existência, não sendo questionado reflexivamente a respeito dos atos intencionais da consciência que o constituem. Na experiência dóxica do mundo, o mundo está sempre lá, passiva e imediatamente dado à consciência como a fundação inquestionada de todos os atos constitutivos da consciência e das próprias ações. (VANDENBERGHE, 2010.p. 284. - Nota 18). 
Vemos com isso que a doxa impõe a consciência dos indivíduos o mundo do senso comum como sendo a própria realidade, por isso que por mais que ocorra uma construção (dos sujeitos e da realidade) essa não é percebida em sua essência. Marx já alertava como conceito de ideologia, que o conhecimento cognoscível da realidade está diretamente relacionado ao da reprodução da vida social. Com essa reprodução social se estrutura uma estrutura de manutenção da desigualdade social e da estrutura simbólica de dominação ideológica. Os vários campos que interiorizamos em nosso percurso existencial do ser no tempo enquanto trajetória de social de vida tem o poder pedagógico de construir a realidade nômica na nossa interioridade psíquica, e na exterioridade coletiva. Um totem, para usar um termo de Freud, que serve como telhado da apreensão sensível do real pela nossa consciência.

Essa manutenção do real no senso comum é inculcada em campos fortemente estruturados como o da educação: "quase todos os grandes princípios de divisão têm sido até agora inculcados ou reforçados pelas instituições escolares cuja missão máxima consiste em construir a nação como população dotada das mesmas categorias logo o mesmo senso comum" (BOURDIEU, 2007. p. 119[1997]).

Ao manter uma realidade enxergada, percebida e representada como natural, a ordem simbólica mantém a sua reprodução social do mundo. Os discursos, representações no imaginário, constantes ocultas que se reproduzem na cultura, reminiscências dos traços mnêmicos do inconsciente. Todos os mecanismos de dominação interiorizados e exteriorizados são reproduzidos e impostos enquanto poder simbólico na construção da realidade.

A construção da realidade social condiciona um modo de vida, um modo de ser no mundo da vida, um aprisionamento do espírito na corporeidade da socialização. Ela mantém as leis invisíveis que insistem em se repetir na reprodução social do mundo que vem em conjunto com a manutenção e fixação da realidade constituída sócio historicamente. Percebemos a realidade como natural enquanto na verdade ela foi naturalizada na instância do real. A constituição da realidade para o sujeito, institui classes sociais invisíveis ao olho nu, impõe no imaginário 
representações inferiores dos homens (classe, raça e gênero), atualiza os registros simbólicos com entidades de dominação a serviço do mal estar social.

Esse feitiço das entidades do mal, não ocorre somente no fetiche da mercadoria de Marx, ele se expande por toda a nossa capacidade de representação e apreensão da realidade, como diz Lacan (1966). Logo, estudar os mecanismos de construção da realidade serve como esporte de combate sociológico contra a manutenção da reprodução sócio simbólica do mundo. As classes dominantes mantêm uma realidade fixa em nossas cabeças enquanto visão de mundo e princípio de conhecimento do real, sendo que outros mundos são possíveis, outras realidades podem ser reconhecidas. Tudo vai depender da luta simbólica de imposição do sentido (BOURDIEU, 1977). Sendo o sentido do mundo, concomitante relacionado com a constituição do sujeito no espaço.

\section{A CONSTITUIÇÃO DO SUJEITO ESPACIAL}

$\mathrm{Na}$ gênese do debate acerca da constituição do sujeito, Aristóteles (1991. p. 28 [323 a.C.]) afirma: "O imitar é congênito no homem, por imitação, aprende as primeiras noções (...). É imitando (dia mimeseos) que adquire seus primeiros conhecimentos (...). Sinal disto é o que acontece na experiência". Esse conceito aristotélico de mimetização/mímica $/ \mathrm{mimesis,}$ é traduzido pelos sociólogos como sendo "socialização", e nela é onde se forma a gênese das primeiras noções do habitus.

O sentido do mundo engendrado pelo habitus tem a sua gênese no campo social da família, nele é onde se constitui a socialização primária que é a mais entrincheirada na consciência no que diz respeito à construção social da realidade (BERGER e LUCKMANN, 2009). Esse sentido do mundo inculcado é o que estrutura os indivíduos na sua formação enquanto sujeitos viventes em um mundo social, o campo de existência formado pela família é o que constitui os indivíduos de um grupo (ser a1), esse campo existencial da presença espacial no mundo pelo dasein 
(HEIDEGGER, 1988 [1927]) é o que impõe o poder temporal ao ser social, e com ele a normatização social do que vem a ser a realidade (nomos).

A identificação inicial dos indivíduos se constitui mimeticamente nas semelhanças familiares, para usar um termo de Wittgenstein. Nela é onde se aprende a codificação da linguagem e as regras do jogo que constituem os corpos (béxis) e a personalidade cognitiva (eidos) na relação com a estrutura social (ethos). A partir das instruções que o homem tem nas relações sociais de seu meio há uma constituição ontológica que o define eticamente enquanto sujeito (ser social). Esse movimento mimético de socialização é o que fornece as bases ontológicas da construção da realidade enquanto disposição na alma dos indivíduos, permeando o alcance de sua compreensão do mundo.

Quando se diz que saber o ABC é um estado da alma, pensa-se assim no estado de um aparelho psíquico (p. ex, de nossocérebro),pormeiodoqualelucidamos as exteriorizações deste saber. Um tal estado chama-se disposição. Mas não é incontestável falar aqui de um estado da alma, conquanto deveria haver dois critérios para o estado, a saber: um conhecimento da construção do aparelho, independente de seus efeitos (o "consciente" e o "inconsciente" e para designar o contraste entre os estados de consciência e disposição. Aquelas duas palavras ocultam uma diferença gramatical). (...) É evidente que a gramática da palavra "saber" goza de um estreito parentesco com a gramática das palavras "poder", "ser capaz". Mas também com a gramática da palavra "compreender" (dominar uma técnica). (WITTGGENSTEIN, 1994.p. 85-6). [1953].

Nessa perspectiva, a constituição do sujeito no espaço é o que vai possibilitar a sua compreensão gramatical do mundo que o circunscreve, ou seja, a "realidade" formada em relação as suas disposições internalizadas no inconsciente para designar estados de consciência de representação do 
real em nosso princípio da visão. Até o que compreendemos por "visão" é comprometido pelo vínculo social, e não uma ótica puramente biológica. O que é percebido depende das categorias mentais que se formam no sujeito, desde a identificação primária com o vinculo social da família.

\begin{abstract}
Dito isso, se é verdade que a família é apenas uma palavra, também é verdade que se trata de uma palavra de ordem, ou melhor, de uma categoria, principio coletivo de construção da realidade coletiva. Pode-se dizer, sem contradição, que as realidades sociais são ficções sociais sem outro fundamento que a construção social e que ao mesmo tempo existem realmente, coletivamente reconhecidas (...) a família é um principio de construção da realidade social, também é preciso lembrar, contra a etnometodologia, que esse princípio de construção é ele próprio socialmente construído e que é comum a todos os agentes socializados de uma certa maneira. Dito de outro modo é um princípio comum de visão e de divisão, um nomos que todos temos no espírito, porque ele nos foi inculcado por meio de um trabalho de socialização concretizado em um universo que era ele próprio realmente organizado de acordo com a divisão em famílias. Esse princípio de construção é um dos elementos constitutivos de nosso habitus, uma estrutura mental que, tendo sido inculcada em todas as mentes socializadas (...), uma lei tácita (nomos) da percepção e da prática que fundamenta o consenso sobre o sentido do mundo social (e da palavra família em particular), fundamenta o senso comum (BOURDIEU, 2011. p. 126-7[1994]) (Grifos do Autor).
\end{abstract}

Tal consenso do senso do mundo tem implicâncias diretas no decorrer do jogo social, especialmente no que diz respeito à manutenção da estrutura de dominação e desigualdade. Isso se dá porque os indivíduos constituídos de maneira diferente, em famílias distintas, meio social diferenciados, não possuem um senso prático igualitário da percepção da realidade social. 
Para Bourdieu o sentido da realidade é definido na prática operada pelos agentes, logo o que é percebido no espaço simbólico depende do que foi constituído no espaço social. Do mesmo modo que na relatividade de Einstein o espaço só pode ser apreendido na posição do observador. $\mathrm{Na}$ perspectiva relacional de Bourdieu a percepção da realidade vai depender da posição relativa que o sujeito ocupa no espaço social:

A noção de espaço contém, em si, o princípio de uma apreensão relacional do mundo social: ela afirma, de fato, que toda a "realidade" que designa reside na exterioridade mútua dos elementos que a compõem. Os seres aparentes, diretamente visíveis, quer se trate de indivíduos quer de grupos, existem e subsistem na e pela diferença, isto é, enquanto ocupam posições relativas em um espaço de relações que, ainda que invisível e sempre difícil de expressar empiricamente, é a realidade mais real (ensrealissimum, como dizia a escolástica) e o princípio real dos comportamentos dos indivíduos e dos grupos. (BOURDIEU, IBID. p. 48-9[1994]). (Grifos do autor).

Vemos que os indivíduos formam o seu comportamento e ação social a partir das noções realistas que formam da exterioridade mútua, com isso essa constituição é feita por meio de uma diferença ontológica que separa a percepção relativa que esses indivíduos têm da "realidade". Como já foi dito, por mais que na aparência o real é percebido no sentido Kantiano de uma "coisa em si", esse é na verdade construído relativamente pelos indivíduos que compõem o mundo. Por isso que a sociologia da prática inaugurada por Bourdieu (2000) se estrutura na perspectiva relacional.

\section{O REAL É RELACIONAL}

$\mathrm{Na}$ perspectiva relacional não existe na totalidade uma realidade objetivamente fechada em si, e sim uma construção da realidade que se faz de maneira relativa a partir da posição ocupada no espaço social e simbólico, ambos dialeticamente interligados. A partir da posição 
ocupada no espaço social se forma o espaço simbólico ${ }^{3}$, e essa relação é o que define o sentido da realidade percebida e decodificada pelos agentes.

A dimensão simbólica é essencial para a decodificação possível do real para os indivíduos socializados na dimensão social, ela impõe a dimensão do sentido aos sujeitos que dividem um mesmo código (linguístico, moral, cultural). Assim sendo, o que é compreendido como real no espaço social depende do que foi constituído e internalizado no espaço simbólico dos indivíduos. A construção da realidade tem uma relação direta com a constituição do sujeito do sentido (LACAN, 1998 [1966]), e essa "mediação simbólica" entre a objetividade das relações sociais (opus operatum) e a subjetividade das disposições mentais (modus operandi) tem o seu sentido relacional organizado pelo habitus (BOURDIEU, 2006 [1990]).

Nesse âmbito, não se tem na essência, uma realidade em si, na representação dos sujeitos coletivos, já que esses sujeitos se constituem de maneira diferente no espaço social. Nesse sentido, o real não é marcado por um realismo positivista em sua essência (somente na aparência, assim como o fetiche de Marx, mas ao invés de ser da mercadoria, ele é o "fetiche da realidade"), e sim por uma relatividade disposicional; ou seja, o real é relacional.

Até mesmo nas ciências rigorosas como a física se tem esse debate acerca do mundo objetivo. Uma comprovação disso é a famosa teoria da relatividade geral de Einstein (2005, [1905]), onde ao criticar o positivismo de Newton (2012, [1687]) que via a realidade como um tempo e espaço fechado em si, o físico da relatividade conclui que assim como o éter depende da eletricidade e do magnetismo para se manifestar, a realidade depende da posição do observador enquanto condição fenomenológica de percepção. Nesse sentido, não existe um realismo absoluto nem concreto, sendo a concepção do que vem a ser a real aquilo que os seres

${ }^{3}$ Como lembra Lacan (1966) com a noção de "nó borromeano", não há separação entre o real e o simbólico, ambos estão dialeticamente conectados por uma economia psíquica que forma o sentido da realidade construída e representado pelo sujeito. (SimbólicoImaginário-Real). 
humanos conseguem decodificar a partir da posição relativa que ocupam no "espaço-tempo".

A perspectiva relacional desenvolvida por Bourdieu segue o mesmo caminho ao criticar as noções positivistas de um mundo social fechado e percebido de maneira igual por todos os agentes (um tempoespaço absoluto). Assim como não há uma igualdade na construção dos indivíduos enquanto ser social, também não se tem a mesma paridade na construção da percepção da realidade.

\begin{abstract}
Costumo citar ligeiramente uma formula célebre de Pascal: "o mundo me contém e me engole como um ponto, mas eu o contenho". O espaço social me engloba como um ponto. Mas esse ponto é um ponto de vista, princípio de visão assumida a partir de um ponto situado no espaço social, de uma perspectiva definida em sua forma e em seu conteúdo pela posição objetiva a partir da qual é assumida. O espaço social é a realidade primeira e última já que comanda até as representações que os agentes podem ter dela (BOURDIEU, 2011, p. 27 [1994]).
\end{abstract}

Podemos encontrar nessa afirmação as premissas da perspectiva relacional da teoria da prática de Pierre Bourdieu. Para o autor, o sentido da realidade é definido na prática operada pelos agentes (senso prático). A realidade que é percebida no espaço simbólico depende do que foi constituída relacionalmente no espaço social (campo). Ou seja, a partir da internalização de uma economia simbólica dos capitais (capital cultural, econômico e social) por meio da socialização familiar e escolar é que se constitui o habitus, e esse define a decodificação da realidade pelos agentes. Essa é a perspectiva relacional de Bourdieu, nela a percepção da realidade depende da posição relativa que o sujeito ocupa no espaço social.

Em síntese, realidade depende da posição ocupada pelo observador no espaço (Einstein), do sujeito em relação mimética com o meio ao seu redor (Aristóteles) na produção das representações constituídas por um 
esquema prático de percepção e ação do mundo que organiza o nosso habitus a partir do que toma uma dimensão de sentido em nosso espaço simbólico (Bourdieu). Nessa perspectiva relacional a percepção vai depender da economia simbólica dos capitais que formam o babitus dos agentes.

Nesse âmago, surge a pseudo crítica positivista a partir da pergunta: se cada indivíduo percebe o real como algo diferente, então por que não vivemos em uma esquizofrenia coletiva com cada pessoa numa realidade fantasiosa diferente, ao invés de uma sociedade integrada? E a resposta bourdieusiana a esse problema, é que isso não ocorre devido ao "poder simbólico".

\section{O PODER SIMBÓLICO}

Esse poder que impõe o sentido do mundo em um tempo histórico ao conjunto coletivo de uma sociedade é o poder simbólico, ele homogeneíza a realidade para todos os agentes, é uma espécie de habitus transcendental do mundo que impõe uma exterioridade mútua à sociedade como um todo. Em cada período histórico a vontade ética da atividade humana é se manter conforme a ordem social, é o traço moral que marcam os homens virtuosos de seu tempo (ARISTOTELES, 1991 [300 a.C.]). Essa é a adequação que ocorre às estruturas objetivas e subjetivas que sustentam a nomos social que é mantida pela illusio (BOURDIEU, 2007 [1997]).

Fica marcada uma vontade dóxica de agir conforme a norma (seja consciente ou inconscientemente), onde é justamente o poder simbólico que normatiza o sentido da realidade para todo o corpo social. Esse fenômeno que impõe o que é percebido pela sociedade é uma nomia do senso comum imposta pelo fato social (DURKHEIM, 1995, [1893]) de maneira legítima (WEBER, 1999 [1913]) a partir das regras seguidas pelas semelhanças familiares dos grupos que dividem uma linguagem (WITTGENSTEIN, 1953) se constituindo como a própria verdade (FOUCAULT, 1996 [1970]). 
Nesse sentido, por mais que a realidade seja construída de maneira relacional a partir de desiguais disposições dos habitus de cada indivíduo, que são incorporadas na mente e no corpo a partir de distintas estruturações sociossimbólicas no seio familiar. Dividimos um mesmo pano de fundo moral na constituição de nosso self, como lembra Charles Taylor (1997). Como esses mesmos indivíduos inseridos na coletividade dividem um pano de fundo moral, cultural e lingüístico marcado pelo poder simbólico, que forma a aparência da ilusão ideológica de uma realidade homogênea perante todo o cosmos social, por mais que na essência se tenha uma estrutura desigual e relacional da relaidade.

A realidade que se mantém arbitrária em um tempo, coisificada no espaço social e simbólico que constituem o sujeito enquanto ser social, se mantém graças ao poder simbólico. Esse poder, reflete a vontade do grupo que se torna dominante na luta de classes simbólica que impera categoricamente a manutenção do sentido nos campos que constituem a realidade, principalmente a família e a escola que são as bases da socialização primária. Nesse âmbito, os sistemas simbólicos que nos circunscrevem nesse meio (linguagem, cultura, religião, mitos) são estruturados como sendo um campo de produção do sentido em nosso habitus.

O mundo prático que se constitui na relação com o habitus como sistemas de estruturas cognitivas e motivadoras é um mundo de fins já realizados, modos de emprego ou movimentos a seguir, e objetos dotados de "caráter teleológico permanente", como diz Husserl, ferramentas ou instituições; isso porque as regularidades inerentes a uma condição arbitrária (no sentido de Saussure ou de Mauss) tendem a aparecer como necessárias, até mesmo naturais, pois estão no princípio dos esquemas de percepção e de apreciação por meio dos quais são apreendidas (BOURDIEU, 2009, p. 88[1980]). (Grifos do Autor).

Vemos a partir da passagem supracitada que a percepção prática do mundo se constitui diretamente na relação com o habitus enquanto 
estrutura cognitiva, e esse não tem uma intencionalidade desinteressada, pelo contrário, segue as regras do meio social em que foi constituído. A visão que os sujeitos têm do mundo objetivo segue arbitrariamente a lógica

do campo sócio-familiar em que eles formaram o seu habitus (formação arbitrária das visões de mundo). Esse meio por sua vez não é autônomo, e sim marcado pelas leis da cultura, do social e do simbólico. A construção dessa estrutura estruturada e estruturante está diretamente relacionada à construção de sua apreensão/representação do mundo.

Desde o momento que aprendemos a falar, já estamos internalizando uma gramática dominante como condição simbólica do pensamento. Estruturamos nossa própria cognição a partir da estrutura lingüística, ou no sentido de Saussure (2006, [1916]), o sistema estruturado da linguagem forma uma razão prática enquanto imagemacústica na consciência. Sendo que essa razão prática que orienta toda nossa representação e ação no mundo social não é mantida unicamente pela linguagem, e sim pelo poder simbólico como construção da realidade, como podemos ver na passagem abaixo:

O poder simbólico é um poder de construção da realidade que tende a estabelecer uma ordem gnoseológica: o sentido imediato do mundo (e em particular, do mundo social) supõe aquilo a que Durkheim chama o conformismo lógico, quer dizer, "uma concepção homogênea do tempo, do espaço, do número, de causa, que torna possível a concordância entre as inteligências". Durkheim - ou depois dele, RadcliffeBrown, que faz assentar a "solidariedade social" no fato de participar num sistema simbólico - tem o mérito de designar explicitamente a função social (no sentido do estruturo-funcionalismo) do simbolismo, autêntica função política que não se reduz à função de comunicação dos estruturalistas. Os símbolos são os instrumentos por excelência da "integração social": enquanto instrumentos de conhecimento e de comunicação, eles tornam possível o consensus acerca do sentido do mundo social que contribui fundamentalmente para a reprodução da ordem social: 
a integração "lógica" é a condição da integração moral. (BOURDIEU, 2006. p. 9-10[1990]).

Nesse âmbito, por mais que exista uma dimensão relacional da realidade a partir do sentido que o sujeito forma na sua constituição ontológica (o real relacional), o poder simbólico funciona no sentido Kantiano de um imperativo categórico que constrói a razão prática de uma realidade dóxica, a homogeneizando para todo o corpo social (cosmos). Para fazer uma analogia com a teoria do valor de Marx, é como se na aparência percebemos a realidade como se ela fosse totalmente em si; enquanto que na essência não temos o acesso total da realidade, já que como a mesma é "construída", à nossa percepção fenomenológica ocorre somente por via da representação e da decodificação de parcelas do real (as que temos acesso consciente). Nesse caso, a nossa vida cotidiana é marcada gnoseologicamente por uma espécie de fetiche da realidade.

Sendo que, esse poder fetichizante da percepção do mundo não funciona no sentido marxista de uma estrutura social que paira exteriormente sobre a consciência dos indivíduos, ela além de fazer esse movimento também é interpelada pelos agentes. Ou seja, existe um duplo movimento que consubstancia a construção da realidade, são eles: a exteriorização na interioridade e a interiorização da exterioridade.

Nessa dialética pendular, ao mesmo tempo em que a estrutura social condiciona os indivíduos que internalizam o poder temporal (construção da realidade social marcada pela exterioridade na interioridade); os agentes também constroem a realidade com seu sentido subjetivo do mundo (construção social da realidade marcado pela interiorização da exterioridade). Esses dois movimentos são inseparáveis na construção do que vem a ser entendido como realidade e na estruturação de um habitus. O sentido do mundo que se torna hegemônico nesse movimento de possibilidades simbólicas (luta pelo sentido), é o que determina o poder temporal que impõe a percepção real do mundo à coletividade. 


\section{CONSIDERAÇÕES FINAIS}

Conclui-se que na teoria de Bourdieu o real é relacional, isso não é uma mera sociologização da filosofia, e sim uma constatação cientifica do movimento do real que perpassa na nossa constituição enquanto ser social. Porém, esse fenômeno não é percebido na compreensão imediata do mundo por causa do conformismo lógico que opera um poder simbólico enquanto norma invisível a ser seguida por todo corpo social, naturalizando com isso a construção relacional do real como se fosse um dado objetivo absoluto natural (violência simbólica).

Nesse âmago, por mais que se tenha uma construção da realidade singular (heterogênea) a partir do que cada sujeito formou na sua mente (eidos) e no seu corpo (héxis) e na estrutura social (ethos) enquanto organização dos fenômenos sociossimbólicos pelo habitus. Essa, a violência simbólica faz com que percebamos a realidade de maneira homogênea (doxa).

Dessa forma, a "realidade" existe enquanto ilusão (a partir da determinação coletiva do sentido do mundo em um momento histórico), ao mesmo tempo em que é construída relacionalmente pelos sujeitos em um movimento dialético (na construção singular de cada disposição do habitus). Isso marca um continuum de múltiplas determinações da construção da realidade na perspectiva relacional.

\section{BIBLIOGRAFIA}

ARISTÓTELES. [323 a.C.] Poética. In: Os Pensadores - vol 2. SP: Nova cultural, 1991.

. [300 a.C.] Ética a Nicômico. In: Os Pensadores - vol 2. SP: Nova cultural, 1991.

- [1 a.C.] Categorias. Trad. Maria J. Figueiredo. Lisboa: Instituto Piaget, 2000. 
BERGER, P. LUCKMANN, T. [1996]. A construção social da realidade: tratado de sociologia do conhecimento. Petrópolis Rio de Janeiro: Vozes, 2009.

BOURDIEU, Pierre. [1972] Esquisse d'une théorie de la pratique. Seuil: France, 2000.

- [1994] Raz̃ões Práticas: sobre a teoria da ação. - Campinas, SP: Papirus, 2011.

. [1980] O senso prático. Petrópolis, RJ: Vozes, 2009.

. [1990] O Poder Simbólico. - RJ: Bertrand Brasil, 2006.

. [1930] Coisas Ditas. SP: Brasiliense, 2004.

.[1997] Meditações Pascalianas. - RJ: Bertrand Brasil, 2007.

. Une classe objet. In: Actes de larechercheensciencessociales. Vol. 17-18, novembre 1977 pp. 2-5.

DA SILVA, Danilo. A Reestruturação do habitus na formação de novos sentidos: Bourdieu com Lacan. $37^{\circ}$ Encontro Anual da ANPOCS, 2013.

DAVIS, K e MOORE, W. Alguns principios de estratificação,in: VELHO, Otavio. Estrutura de Classes e Estratificação Social. RJ: zahar, 1979.

DOMINGUES, J.M. Teorias sociológicas no século XX. - Rj: Civilização Brasileira, 2008.

DURKHEIM, Émile. [1893] As regras do método sociológico. - SP: Martins Fontes, 1995.

. Sociologie et Philosophie. Paris: PressesUniversitairaires de France, 1951.

[1912] As formas elementares da vida religiosa. SP: Martins Fontes, 1996.

EINSTEIN, Albert. [1905] O ano miraculoso de Einstein: cinco artigos que mudaram a física. RJ: Ed UFRJ, 2005. 
FOUCAULT, Michel. A ordem do discurso: Aula inaugural no College de France, pronunciada em 2 de dezembro de 1970. - São Paulo: Ed Loyola, 1996.

FREUD. Sigmund. [1900] A interpretação dos sonhos. RJ: imago, 2001. . [1913] Totem e Tabu. RJ: Imago, 2006.

FREYRE, Gilberto. [1936] Sobrados e Mocambos. - SP: Global, 2006.

HANKS, William. Lingua Como Prática Social: das relações entre língua, cultura e sociedade a partir de Bourdieu e Bakbtin. RJ: Cortez, 2008.

HEIDEGGER, Martin. [1927] Ser e Tempo. RJ, Petrópolis: vozes, 1988.

HUSSERL, Edmund. A Idéia de Fenomenologia. Lisboa: Ed 70. 1989.

LACAN, Jacques. (1966). Escritos. RJ: Jorge Zahar, 1998. . (1975-6). O Seminário, livro 23 - O sinthoma. - RJ:Zahar, 2007

MAFRA, Taciana. A Estrutura na Obra Lacaniana. RJ: Companhia de Freud, 2000.

MARX, Karl. [1845-6] A ideologia alemã. SP: Boitempo, 2007.

MEUCCI, Artur. O papel do habitus na teoria do conbecimento: entre Aristóteles, Descartes, Hume, Kante Bourdieu. Dissertação de Mestrado do Programa de Pós Graduação em Filosofia da Usp: SP, 2009.

MICELI, S. A força do sentido. In: BOURDIEU, P. Economia das trocas simbólicas. SP: Perspectiva, 2009.

NEWTON, Isaac. [1687] PRINCIPLA: Princípios Matemáticos de Filosofia Natural. SP: Editora da Universidade de São Paulo, 2012.

ORTIZ, Renato. Introdução. In: Pierre Bourdieu - Sociologia. - SP: Ática, 1994.

SAUSSURE, Ferdinand. [1916] Curso de Linguística Geral. - SP: Cultrix, 2006. 
SCHUTZ, A. Collected Papers I: The problemof social reality. The Hague, Martinus Nijhoff, 1962.

SEARLE, John. La construction de la realité sociale. - Paris: Gallimard, 1995.

SOUZA, Jessé. A ralé brasileira: quem é e como vive. BH: Editora UFMG, 2009.

TAYLOR, Charles. As fontes do self - a construção da identidade moderna. SP: Ed Loyola, 1997.

VANDENBERGHE, Frederic. Teoria Social Realista: um diálogo francobritânico. BH: Ed UFMG; RJ: IUPERJ, 2010. - As sociologias de Georg Simmel. SP: Edusc, 2005.

WEBER, M.[1904] A "objetividade" do conbecimento nas ciências sociais. SP: Ática, 2006. - [1913] Economia e Sociedade: fundamentos da sociologia compreensiva. Brasília, DF: Editora Universidade de Brasília: São Paulo: Imprensa Oficial do estado de São Paulo, 1999.

WITTGENSTEIN, Ludwig. [1953] Investigações Filosóficas. SP: vozes,1994. 